\title{
LEITORES, LEITURAS E OS LIVROS DO PNBE NA E PARA A EDUCAÇÃO DE JOVENS E ADULTOS
}

Prof. Dr. Délcio Antônio Agliardi

d.agliardi@terra.com.br Docente da Universidade Caxias do Sul 
RESUMO: Este artigo é um recorte da pesquisa desenvolvida para a elaboração de tese de doutoramento em Letras. O estudo tem como objetivo explorar o impacto da política educativa prevista no Programa Nacional Biblioteca da Escola (PNBE), voltada à literatura na escola contemporânea. Os estudantes de uma escola pública municipal de ensino fundamental, matriculados na modalidade Educação de Jovens e Adultos (EJA), representam as vozes empíricas para a compreensão do problema de pesquisa. Tem sustentação teórica nos estudos que defendem a literatura como direito humano (CANDIDO, 2004), a experiência de ler (LEWIS, 2003), a leitura como forma de ajudar os jovens a constituírem e a se tornarem artífices de suas vidas (PETIT, 2013). Por intermédio de pesquisa-ação e outros procedimentos metodológicos foi possível compreender a história de leitura dos jovens, as funções da biblioteca escolar e os dilemas para apropriação da leitura como fonte sociocultural, tendo por base os acervos distribuídos pelo PNBE.

PALAVRAS-CHAVE: Leitura literária, PNBE/EJA, experiência de ler.

\section{READERS, READING AND THE PNBE BOOKS IN AND FOR EDUCATION OF YOUGN ADULTS AND ADULTS}

ABSTRACT: This paper is part of a study carried out for a doctoral thesis in Letters. The study aims at exploring the impact of an educational policy called Programa Nacional Biblioteca da Escola (National Program for School Libraries, PNBE), which focuses on literature in the contemporary school. Students from a primary municipal public school and registered at EJA (Adults and Young Adults Education) represent the empirical voices for the understanding of the research problem. Theoretical support is based on studies on literature as a human right (CANDIDO, 2004), on the experience of reading (LEWIS, 2003), and on reading as a way of helping young people to become craftsman of their own lives (PETIT, 2013). By means of action-research and other methodological procedures it was possible to understand young adults' reading history, the functions of the school library and the dilemmas concerning appropriation of reading as a socialcultural source, based on the collections distributed by PNBE.

KEYWORDS: Literary reading, PNBE/EJA, experience of reading. 


\section{Introdução}

Todas as atividades que têm a literatura como objeto central serão promovidas para fazer do País uma sociedade leitora. $\mathrm{O}$ apoio de todos que assim compreendem a função literária, a proposição é indispensável. Se é um projeto literário é também uma ação política por sonhar um País mais dignoํ.

A partir das novas conquistas na área da educação brasileira anos 2000, quando da elaboração e da implementação da legislação e das políticas públicas de currículo escolar, avaliação e direitos de aprendizagem e desenvolvimento de crianças, jovens e adultos, sobretudo pela aprovação das novas Diretrizes Curriculares Nacionais da Educação Básica (DCNEB/2010) e do financiamento público (FUNDEB), fruto de um longo processo de discussão, a Educação de Jovens e Adultos (EJA) é considerada uma modalidade da Educação Básica. Neste documento, a Educação Básica é compreendida como um projeto orgânico, sequencial e articulado em níveis e modalidades, além de garantir os direitos de aprendizagem e desenvolvimento de crianças, jovens e adultos. Deste modo, a EJA passou a ter ainda mais importância enquanto função social para o alargamento do processo de escolarização de 9 anos no Ensino Fundamental e Ensino Médio. A conquista dos direitos de aprendizagem e desenvolvimento dos estudantes matriculados é outra novidade. Pela força da regulamentação da legislação e da política educativa nacional, todo e qualquer brasileiro tem o direito à matrícula e frequência escolar independentemente de ter ou não estudado na idade certa. O Exame Nacional para Certificação de Competências de Jovens e Adultos (ENCEEJA) permite a conclusão do Ensino Fundamental e Médio por meio de provas estruturadas nas áreas do conhecimento, estabelecidas a partir do currículo da Base Nacional Comum Curricular (BNCC/2017), de acordo com os Parâmetros Curriculares Nacionais (PCN's).

A aquisição de obras literárias pelo Governo Federal por intermédio de editais públicos do Programa Nacional Biblioteca da Escola (PNBE) e o incentivo às bibliotecas escolares para que os estudantes possam dominar a cultura letrada são ações de caráter sociocultural com potencial para qualificar a leitura e a escrita de crianças, jovens e adultos. O PNBE passou a atender nos anos pares, a partir de 2010, também as escolas da EJA de todo o País. São selecionados, adquiridos e distribuídos acervos compostos por obras de literatura de diferentes gêneros literários: poema, conto, crônica, novela, teatro,

\footnotetext{
${ }^{1}$ Epígrafe extraída do Manifesto por um Brasil Literário, escrito por Bartolomeu Campos de Queirós, 2009.
} 
texto da tradição popular, romance, livros de imagens, histórias em quadrinhos, entre outros, visando fomentar à leitura literária de alunos e professores.

Na perspectiva dos livros, das leituras e do leitores da EJA, o presente trabalho tem como base a pesquisa para a construção de tese de doutoramento em Letras (20132016), acerca da experiência de leitura de jovens e adultos em processo de escolarização tardia. Durante o estágio de investigação doutoral, realizado no Instituto de Educação da Universidade de Lisboa (2016), foi possível confrontar as experiências de incentivo à leitura desenvolvidas no Brasil e em Portugal, pois nos dois países está em curso a implementação de planos nacionais de leitura, associados às demandas crescentes pelo domínio da língua materna, considerada competência-chave para a inclusão no mundo contemporâneo.

Os principais resultados da pesquisa mostram que a experiência de ler e a história de leitura é a história de cada um dos seus leitores; o domínio e o fortalecimento da cultura letrada esperados pelo PNBE passam necessariamente pela formação do professor bibliotecário, pelo incentivo na qualificação dos espaços e lugares de leitura e pela mediação; as funções da biblioteca escolar vinculam-se ainda ao currículo escolar; a experiência de ler muda o percurso da autoformação daqueles estudantes que não tiveram acesso à escola no tempo próprio.

Este estudo é uma contribuição para a educação, comunidade científica e interessados no assunto acerca da experiência de leitura literária por intermédio de uma abordagem construída no interior de uma escola pública com estudantes jovens e adultos, suas leituras de mundo e da palavra, a partir das obras disponibilizadas às bibliotecas das escolas. Pretende ainda contribuir com a discussão da experiência de leitura no processo de escolarização e apropriação de competências no âmbito do domínio de linguagens, compreensão de fenômenos, enfrentamento e resolução de situações-problema.

\section{Os percursos metodológicos da pesquisa}

A pesquisa desenvolvida é ancorada na abordagem exploratória e de natureza qualitativa. A metodologia pesquisa-ação (THIOLLENT, 2011) é utilizada como um recurso flexível e associado a outros procedimentos de pesquisa para a construção dos dados empíricos de campo. Entrevistas individuais e coletivas, questionários semiestruturados, rodas de leitura, observação participante e análise de realidade constituíram-se em procedimentos flexíveis nos percursos metodológicos da pesquisa. 
Diferente das pesquisas elaboradas segundo o modelo clássico da investigação científica em que os procedimentos se caracterizam pela padronização, a pesquisa-ação permite a redefinição de hipóteses e dos elementos que vão surgindo nos percursos.

Por conveniência e intencionalidade, a amostra da pesquisa se compõe de estudantes da EJA de uma turma da Totalidade Múltipla de Conhecimento (TMC) dos anos finais do Ensino Fundamental de uma escola pública de Caxias do Sul/RS. Os critérios adotados para a seleção da amostra foram delimitados assim: (a) estudantes de escola pública; (b) estudantes que não tiveram acesso à educação escolar na idade própria; (c) participantes de uma turma de TMC da modalidade EJA; (d) estudantes homens e mulheres; (e) estudantes de idade acima de 30 anos de idade. A intencionalidade tornou a pesquisa mais rica em termos qualitativos pela razão do perfil dos estudantes escolhidos.

Ao longo dos estudos para a construção da tese de doutoramento em Letras, buscou-se a elaboração do Estado da Arte acerca de leitura literária na EJA a partir dos trabalhos da Associação Nacional de Pós-Graduação e Pesquisa em Educação (ANPEd), publicados no portal nos últimos 10 anos. O Ciclo de Política Educativa (BALL, 2011; 2013) possibilitou a análise da concepção e das práticas de política de leitura do PNBE, bem como a exploração da experiência da rede de bibliotecas escolares portuguesas como forma de compreensão da política educativa de leitura no Brasil. Para análise e interpretação dos dados seguiu-se com passos semelhantes aos da pesquisa clássica: categorização, codificação, tabulação, análise e interpretação dos dados obtidos empiricamente.

Considerando que os estudantes da EJA tiveram o direito à educação e à literatura ameaçados ou violados pelo Estado brasileiro, uma vez que não tiveram acesso à educação escolar na idade própria, este estudo trouxe as contribuições teóricas de Candido (2004) a respeito dos bens imateriais.

\section{O direito à literatura na Educação de Jovens e Adultos}

O ideal de formação humana tem larga problematização entre diferentes povos e fases da história da humanidade. O conceito de paideia tornou-se o ideal educativo da Grécia, o de bildung do povo alemão e o de humanitas do povo latino-americano, e esses conceitos aparecem entrelaçados com a cultura, com os valores humanos, com direito de aprender a conviver para alcançar a excelência humana. 
Os documentos internacionais de direitos humanos, sobretudo os gerados no período Pós-Guerra, como a Declaração Universal dos Direitos Humanos da Organização das Nações Unidas (1958) e os esforços da sociedade para tornar a educação um direito, resultaram no aprimoramento dos saberes e no alargamento da educação escolar. Porém, esses bens imateriais não são distribuídos de forma igualitária para todos.

Na Educação de Jovens e Adultos, além do direito à escola àqueles que não tiveram acesso ou continuidade de estudos no ensino fundamental e médio na idade própria (art. 37 da LDB), houve a garantia sociojurídica dos alunos usufruírem dos mesmos benefícios do ensino regular, como formação continuada de professores, material didático-pedagógico, formação profissional ${ }^{2}$ e a inclusão de acervos de literatura pelo PNBE, visando promover direito à literatura. Esses avanços para a qualidade da EJA resultam de um conjunto articulado de respostas para os problemas da educação escolar e da cultura contemporânea.

No período recente da implantação da política pública de educação e cultura para jovens e adultos, o Ministério da Educação criou o Concurso Literatura para Todos (2005), como uma das estratégias da política educativa de leitura, a qual procura democratizar o acesso à leitura, constituir um acervo bibliográfico literário específico para jovens e adultos recém- alfabetizados e criar uma comunidade de neoleitores ${ }^{3}$. Este contexto de práticas socioculturais, estimuladas pelas política pública de leitura, poderá influenciar mudanças para a garantia do direito à literatura.

De acordo com Candido (2004), o direito à literatura pode ser classificado como um bem incompressível. Um direito que não pode ser negado a ninguém, portanto. $\mathrm{E}$ nesta perspectiva, Candido inclui a literatura como um direito humano fundamental a ser reconhecido como indispensável para nós e para o próximo. A experiência de ler Dostoiévski, Drummond ou Lispector não deveria ser privilégio de poucas pessoas.

Nesta direção, os resultados da pesquisa para a elaboração da tese de doutoramento em Letras sinalizam que as obras de literatura, entregues pelo PNBE a todas as escolas do País, as quais respondem o Senso Escolar Anual, constituem-se em literatura potencial, isto é, livros na prateira da biblioteca da escola não favorecem à formação do gosto literário, nem a garantia da literatura como direito humano

\footnotetext{
${ }^{2}$ De acordo com o Plano Nacional de Educação, a meta é triplicar, até 2024, as matrículas da Educação Profissional Técnica de nível médio, assegurando a qualidade da oferta e pelo menos $50 \%$ da expansão no segmento público.

${ }^{3}$ Conceito formulado por Tiepolo (2009), ou seja, o neoleitor é o jovem ou adulto que está iniciando sua caminhada de leitor.
} 
fundamental. É preciso ir além da oferta de livros às escolas. A biblioteca da escola em ação tem como pressuposto a mediação de leitura e sua função é multiplicar, prolongar e preservar experiências literárias.

O estudo mostra ainda que as funções da biblioteca escolar sofreram mudanças ao longo do curso histórico, desde a função de guarda e preservação ao incentivo à leitura de fruição. Assim, uma das análises realizadas tem foco nas alterações das funções da biblioteca escolar: A primeira fase (300 a.C - 500) tem como função a preservação e guarda de obras; A segunda fase (500-1800) de preservação, guarda disponibilização restrita; a fase seguinte (1800-1940), de organização documental, investimento na acessibilidade, primeiros passos na formação de usuários; a quarta fase (1940-1980), de organização documental, investimento na acessibilidade, primeiros passos na formação de usuários, a biblioteca como negócio público ou privado. Na fase mais contemporânea (1980-hoje), sua função está associada à experiência do usuário, desenvolvimento de competências múltiplas para acesso e processamento da informação, apoio à pesquisa e à informação.

Caberá à biblioteca escolar pôr a literatura em ação, no sentido de ensinar aos alunos da EJA a apreciar os livros do PNBE. Há diversas possibilidades para isso: o mesmo livro pode ser lido de vários modos; os projetos de literatura na escola são recursos inteligentes para aproximar crianças e jovens dos mistérios da vida e possibilita o prazer de saborear o que historicamente foi construído pela humanidade; a experiência de ler modifica o percurso de formação do aluno; o professor e o bibliotecário da escola são mediadores essenciais para a formação do gosto literário; a experiência dos alunos com as narrativas e as fábulas dos anos iniciais do ensino fundamental deveria ser potencializada nos anos finais e ensino médio; a leitura humaniza o homem, na medida em que nos tornamos mais solidários com espécie depois de termos lido uma obra literária.

Se o livro e a leitura são tão poderosos no mundo da cultura, como é possível adolescentes e jovens não gostarem de ler? Há diversos fatores que contribuem para afastar ou aproximar o jovem da leitura. Um dos fatores tem relação com o dever, outro como o prazer de ler. O prazer de ler inspira, cria possibilidades diversas das coisas imaginárias, elabora o pensamento reflexivo, dá força para enfrentar as adversidades. De acordo com o Pennac (1993, p. 15), "a aversão pela leitura fica ainda mais inconcebível 
se somos de uma geração, de um tempo, de um meio e de uma família onde a tendência era nos impedir de ler".

A escola pode ser um lugar central de irradiação de práticas de leitura. A biblioteca escolar um espaço de democratização do acesso à cultura letrada. Num dos ensaios de Castrillón (2011) sobre o direito de ler, a autora compreende e justifica que não há escola capaz de fazer mudanças se a leitura não é comprometida como o horizonte para o conhecimento. Para isso, o bibliotecário se torna um mediador fundamental, na medida em que a escola é o único espaço de acesso à leitura para a grande maioria de habitantes da América Latina.

A leitura como dever é analisada por Pennac (1993). A arte de ler resumos, sinopses, fichas de leitura que outros escreveram sobre obras para trabalhos na escola, exames de vestibular ou Exame Nacional do Ensino Médio (ENEM), são práticas sociais que servem à escolarização, mas não servem necessariamente ao amor pelos livros e pela leitura. É uma contradição propor a leitura como obrigação. De acordo com Pennac:

Uma só condição para se reconciliar com a leitura: não pedir nada em troca. Absolutamente nada. Não erguer nenhuma muralha fortificada de conhecimentos preliminares em torno do livro. Não fazer a menor pergunta. Não passar o menor dever (PENNAC, 1993, p. 121).

Nesta perspectiva, a leitura é vista como ato de comunicação, um objeto de compartilhamento. E se pudéssemos fazer o inventário das grandes leituras, o resultado seria este: aquilo que lemos de mais belo deve-se, quase sempre, a uma pessoa querida. Ou seja, a experiência de ler tem relação com quem nos ajudou a despertar o prazer de saborear um bom texto: contadores de histórias, professores, bibliotecários, familiares.

\section{Os jovens estudantes, a leitura e os livros de literatura do PNBE}

A investigação sobre livros, leituras e leitores da política educativa, arquitetada enquanto seleção e distribuição de obras literárias a escolas públicas do País (PNBE), possibilita analisar e discutir o espaço e o capital cultural da biblioteca em relação à cultura letrada. Dessa forma, a reflexão sobre a biblioteca escolar não se esgota e tampouco se encerra. Naturalmente, a biblioteca escolar existe porque há educação escolar crescente e ambas existem porque há crianças, jovens e adultos com o direito de aprender e se desenvolver, previsto nas recentes DCNEB (2010).

Pensar a relação da biblioteca escolar com a cultura letrada do País constitui uma tarefa nada fácil, porque no processo de consolidação e ampliação dos sistemas escolares 
das sociedades desenvolvidas, a partir do século XIX, as funções da biblioteca escolar vinculam-se ainda ao currículo. As práticas e os usos da biblioteca escolar estão distantes dos discursos sobre a importância em termos de disposição de infraestrutura de qualidade, acervos e mediação de leitura, pois a precariedade e as carências são marcas visíveis na arquitetura das escolas do País, bem como as lacunas dos projetos de leitura ou ainda a ausência deles.

O livro foi tratado de distintos modos desde o Brasil colônia e a síntese dessa realidade foi descrita por Lajolo e Zilberman (1996) como sendo de um Brasil colônia sem livros e leitores, situação que se estendeu até meados do século XIX, quando Dom João VI trouxe de Portugal a primeira biblioteca.

Somente com a vinda de Dom João VI ao Brasil (1808), quando ocorreu a criação de escolas e da imprensa, nasce o processo da popularização da leitura e do livro. A baixa importância atribuída ao livro e à leitura ao longo da história do Brasil mantém estreita relação com o processo de escolarização da população e os altos índices de analfabetismo, verificados até hoje.

Estudo sobre a realidade das bibliotecas escolares (CAMPELLO et al, 2012) indica que, de modo geral, são espaços para depositar livros e estão localizadas em salas ou áreas inúteis para outras atividades de ensino. Não têm tamanho suficiente e nem o acervo necessário para merecer o nome de biblioteca. Na maioria das instituições escolares, até mesmo as mais antigas, o lugar da biblioteca ainda não foi conquistado para os fins pretendidas à aprendizagem e ao desenvolvimento intelectual e afetivo dos alunos.

Com efeito, as recentes conquistas no âmbito das políticas públicas educacionais no Brasil, sobretudo em termos do direito à educação de crianças, jovens e adultos, e do alargamento da escolarização, exigem condições objetivas para o funcionamento da biblioteca escolar em três turnos. Esta conjuntura tem possibilitado outra dinâmica na distribuição do tempo para a comunidade escolar, embora a realidade não se mostre ideal ainda. Os alunos da EJA, modalidade desenvolvida quase sempre à noite, de modo geral têm atendimento reduzido na biblioteca da escola, quando existe.

Outro dilema diz respeito ao professor que exerce a função de bibliotecário da escola. A formação desse profissional e os projetos de leitura por ele desenvolvidos são essenciais para a circulação do livro e formação do gosto literário. Além de conhecer o acervo de obras disponíveis é desejável que o profissional responsável pela biblioteca escolar conheça os livros do PNBE e exerça influência sobre os leitores. Na visão de 
Ranganathan (2009), foi preciso muito tempo para se perceber que o bibliotecário deve possuir formação e cultura ampla, pois a tarefa de ensinar pressupõe encontrar para cada pessoa o livro que lhe seja adequado, que deve persuadir a pessoa a se beneficiar do conhecimento entesourado nos livros, a auxiliar na educação ao longo da vida.

O leitor, ao procurar dicas de leitura e orientações do bibliotecário, exercerá influência sobre o circuito sociocultural na escola. Por isso, os projetos de leitura da e na escola, se arquitetados com o planejamento do professor e apoiados pelo bibliotecário, permitem a melhoria da qualidade do ato de ler. Lendo textos, descobrem novas inspirações para a aprendizagem, pois um texto ficcional é capaz de construir o saber de forma criativa e inusitada, leve e precisa. Portanto, a biblioteca é um espaço sociocultural, mais do que complemento didático das atividades cotidianas de uma escola. Ela poderia estar a serviço da construção de espaços vivos de formação de novos leitores, ampliando a capacidade de diálogo com o capital cultural da comunidade escolar da EJA.

Essas são questões imbricadas com a própria concepção de práticas de leitura, concepção essa considerada adequada e compartilhada na educação escolar. Trata-se de configuração simbólica sobre o papel da leitura na civilização ocidental, quando o livro passou a ter papel primordial no sistema escolar. Assim, a política de leitura, prevista no PNBE, pretende colocar em prática a ideia de que livros de qualidade podem servir a professores e alunos da EJA, visando fortalecer a concepção de que a leitura ensina-se, vive-se, prolonga-se nas outras atividades pedagógicas da escola.

\section{Achados de pesquisa e discussão}

A pesquisa-ação adotou diversos procedimentos para a compreensão do alcance da política de leitura, prevista no PNBE, de modo articulado com a história de leitura dos participantes da EJA. Como construção investigativa na área de Letras, em diálogo interdisciplinar, o problema sociocultural dos alunos da EJA enquanto práticas de leitura serviu de pressuposto.

A história de leitura dos participantes apresenta-se como movimento complexo das tensões que emergem do cotidiano. Expressões nativas surgidas no decorrer da pesquisa foram tomadas como elementos de orientação para a articulação entre as dimensões do ler e do viver. Tem significado para os alunos da EJA o conjunto de práticas socioculturais da educação não formal, na perspectiva da auto e da heteroformação, que se articula com as práticas de educação escolar. As vozes dos interlocutores empíricos da 
pesquisa foram analisadas na perspectiva das tensões geradas pela leitura no universo da experiência de vida dos participantes. A ligação entre trajetória pessoal e itinerário de leitor mostram as incidências de práticas de leitura desde a oralidade à leitura da palavra.

A experiência de ler de cada um dos participantes e a experiência compartilhada de leitura são arranjos inscritos em uma partitura de compreensão e reflexão sobre o processo complexo de utilização de competências cognitivas, afetivas e intelectuais a serviço da linguagem humana. A obra Libros, lectores y mediadores, de Pedro C. Cerrillo et al (2002), mostra que a leitura pode ser uma fonte de informação, de aprendizagem e de diversão, ao mesmo tempo em que é um processo gerador de paixões e provocador de fidelidades. Do mesmo modo, pode ser uma aventura complexa, capaz de produzir desenganos, frustrações e aborrecimentos.

Cada participante da pesquisa foi tomado com potencial testemunho sobre a adesão, experiência e formação do gosto literário. Não há como prever se o neoleitor tornar-se-á um grande leitor, quando ocorre o gosto e o fascínio pelo livro. Ou ainda, projetar situações que motivam a rejeição/desinteresse a tal prática. Assim, o cotidiano, a experiência de vida, provoca ou modifica a atração pela leitura, transforma a maneira de compreender e interpretar o texto de ficção.

A história de leitura dos alunos da EJA permite o inventário das diferenças entre o passado e o presente, comparando experiências vividas, contribui para a constituição da identidade de quem escreve e de quem lê. Para esses alunos da EJA, a literatura oferece suporte, reflexão, encoraja, ajuda a superar momentos difíceis. Os dados da pesquisa de campo mostram que a experiência de ler provoca situações de crise, particularmente propícias para o contato com o simbólico. Os momentos de configuração ou ruptura biográfica e de identidade, de culminância de uma etapa do ciclo da vida (por exemplo, infância ou juventude) são circunstâncias favoráveis ao aparecimento do desejo de ler ficção.

Ao abordar o tema Estratégias para a construção de leitores, a antropóloga e pesquisadora Michèle Petit (2013), manifesta-se preocupada com o problema de como a leitura pode ajudar as pessoas a se constituírem, a se tornarem um pouco mais autoras de suas vidas, mesmo quando se encontram em contextos sociais desfavoráveis. Noutra publicação (2008), sobre Os jovens e a leitura, a autora afirma que a biblioteca e a leitura são lugares onde o leitor encontra armas que o encoraja na afirmação de si, onde se distancia do que havia conhecido até então. Atualmente há, talvez, diminuição do número 
de leitores assíduos, contudo a juventude continua sendo o período da vida em que a atividade de leitura é mais intensa. Além disso, por meio da leitura, mesmo esporádica, os jovens podem se preparar para resistir aos processos de marginalização, porque os ajuda a se construir, a imaginar outras possibilidades, a sonhar e a pensar, nesse momento histórico em que o pensamento crítico se apresenta escasso.

Como estratégica visando a coleta de informações pertinentes à experiência de ler, os participantes da pesquisa envolveram-se em rodas de leitura e entrevistas, grupais e individuais. Importante recordar que a arte de promover a leitura é recente, pois ao longo da história foi proibida, sob o argumento dos perigos que uma ampla difusão poderia causar (MANGUEL, 1997). Atualmente, reconhecemos a importância da promoção dos direitos culturais na escola: o direito de saber e de imaginar, de se apropriar dos bens culturais que contribuem para a construção de si, para o exercício da fantasia, sem a qual não há pensamento e construção do conhecimento, na direção proposta por Petit (2008).

Pela educação escolar, os estudantes da EJA reelaboram os saberes da experiência e tornam-se capazes para lidar com as novas descobertas e com o imaginário, a fim de produzir significado e estabelecer relações entre as pessoas, a comunidade e o mundo. De acordo com Pennac (1993, p. 167), "o homem constrói casas porque está vivo, mas escreve livros porque se sabe mortal. Ele vive em grupo porque é gregário, mas lê porque se sabe só". Esse entendimento, enquanto pluralidade humana, condição básica da ação e do discurso, na perspectiva do pensamento de Arendt (2005), provoca comunicação simbólica e pertencimento.

Portanto, o desejo de pensar e de agir, a curiosidade, o prazer de ler, entre outros, não podem ser privilégio de poucos. Esses jovens têm direitos culturais: o direito ao saber, ao imaginário, de se apropriar dos bens culturais, à fantasia. Esses princípios estão consagrados nas disposições do Estatuto da Criança e do Adolescente, na Lei de Diretrizes e Bases da Educação Nacional e noutras legislações da educação brasileira.

Dayrell (1999) procura compreender a escola como espaço sociocultural, sob ótica ampliada da observação densa do fazer cotidiano, pois nela se encontram e convivem alunos e professores como seres sociais e históricos. Por isso, os jovens se apropriam do espaço escolar de forma diversificada, dando-lhe outros significados, enquanto sujeitos que possuem uma historicidade, visões de mundo, valores, sentimentos, emoções, desejos, projetos, hábitos e sonhos. 


\section{Leituras de vida, realidade e ficcção: outras discussões}

A leitura está presente na nossa vida de diferentes formas. Lemos notícias, informações, documentos, peças de publicidade, manuais, legendas de filmes e séries televisivas, informações de trânsito e mobilidade urbana, páginas de Internet, anúncios de outdoors, bulas de medicamentos, mensagens das redes sociais, etc.

A reflexão sobre o ato de ler permite sublinhar a pluralidade que lhe é específica, entendida como uma prática social em toda a sua totalidade, e não somente como uma prática cultural. Assim, a leitura é uma diversificada prática cultural e suas funções sociais são amplas. A leitura é portadora de uma práxis sociocultural, vivida tanto no domínio da fruição e do lazer, como no âmbito da obrigatoriedade escolar e das indispensáveis exigências do mundo do trabalho. Abrange gênero, práticas profissionais, constitui-se numa referência na estratificação e no status social, no exercício do Eu que constrói a personalidade íntima.

As maneiras de ler, por outro lado, de apropriação dos conteúdos e dos diferentes textos, variam de um para outro grupo social, de acordo com as tradições, os interesses e as expectativas. No interior de cada grupo social, ocorrem múltiplas variações nas práticas de leitura. Isso depende de como as práticas de leitura integram-se nos modos de viver, nos valores e crenças de diferentes grupos sociais.

Os resultados da pesquisa de campo em termos do uso das obras de literatura do PNBE, sinalizam que as escolhas de leitura pelos sujeitos da EJA são marcadas por diferentes condicionantes. Há uma relação frágil entre a função pedagógica da biblioteca escolar voltada à pesquisa e à informação aos alunos e à leitura de fruição e de prazer.

Entretanto, os resultados da pesquisa indicam que a professora da EJA e a bibliotecária têm papel relevante na formação do leitor, ao estimular e incentivar seus alunos na prática de leitura. Na voz de uma aluna, participante da pesquisa, quando a professora lê um fragmento de ficção na sala de aula é como uma isca jogada para ela buscar o livro de literatura na biblioteca escolar.

Essa observação de campo comunica que o professor da escola básica exerce influência direta na formação do gosto literário dos alunos. "Procurar o livro" pode ser uma expressão lida como ir à biblioteca escolar, localizá-lo, pedir por empréstimo, leválo embora da escola, usufruí-lo. Significa acessar o livro na íntegra, navegar pela sua 
história, habitar nele. Manguel (1997) insinua que o leitor não lê livros, habita neles, entre suas linhas.

$\mathrm{Na}$ escola em que a pesquisa se desenvolveu, observamos a importância da mediação do bibliotecário e do professor da EJA nas estratégias construídas em sala de aula para uma pedagogia do texto, fundamental para o indivíduo vivenciar a complexidade da prática literária que não se compõe exclusivamente de textos literários, mas do conjunto por estes inspirados.

Nesse sentido, o empenho docente mostra-se necessário para pensar a importância da motivação, pois, em nome da motivação, a obra literária pode circular na prática escolar. "Ou o texto dá sentido ao mundo, ou ele não tem sentido nenhum". (LAJOLO, 2000, p. 15). Na visão desta autora, as atividades que manuais escolares propõem, como oferecer palavras cruzadas, sugerir identificação de um personagem, dramatizar textos e similares, é periférico ao ato de leitura, ao contato profundo que o texto literário pede.

A expressão nativa utilizada por uma das alunas da EJA, "a professora lê um fragmento e eu vou procurar o livro", representa um ato de incentivo à leitura despertado pela professora. Fica evidente que ela estabelece uma relação entre a sala de aula e a biblioteca, entre o fragmento e a obra completa, entre a experiência reduzida da leitura do excerto em sala de aula e o acesso à obra inteira. Independente do capital escolar e cultural, o aluno vê abertura para novas experiências de ler, insinua o prazer de ler e as apropriações que dele faz.

Neste cenário, foi preciso trabalhar com a história de leitura dos alunos da EJA, a partir da compreensão de cada um deles. Texto e leitor, na situação vivida na escola, ultrapassam a solidão individual e entrelaçam-se pelas interações. Este abraço que o texto possibilita é a soma das diferenças, movida pela emoção, estabelecendo um encontro fraterno e possível entre leitor e escritor.

A literatura abre espaços para o leitor imaginar lugares, criar a sua própria cidade, fundar atos de leitura nesse universo mágico, criado para satisfazer desejos sem os quais a existência humana seria muito pobre. De acordo com Queirós (1999), cada palavra descortina um horizonte, cada frase anuncia outra estação, abre caminhos para a viagem do pensamento.

Atualmente, a concepção de leitura tem sido repensada a partir de uma série de debates e trabalhos acadêmicos que a concebem como uma questão ao mesmo tempo 
pedagógica, linguística e social (ORLANDI, 1988). Ler pode significar modos de vida, experiências de um lugar, energia para enfrentar as adversidades.

Zilberman (1988) defende a leitura como atividade humana, algo a mais que a simples decodificação e a compreensão do sentido dado no próprio texto. Nessa concepção, a leitura implica também produção e construção de sentidos, processo no qual o sujeito se constrói como leitor em interação com o texto, com outros textos, a partir de sua própria história de leitor e de suas experiências de vida. Assim, o acesso a bens culturais é condição fundamental no processo de constituição do leitor, ao mesmo tempo em que é essencial realizar um trabalho com a leitura que permita reflexionar acerca dessas relações, dos sentidos apreendidos a partir do texto e dos sentidos produzidos e reconstruídos pelo leitor.

As fronteiras entre o real e o imaginário diminuem porque os fatos da vida se entrelaçam com a abundância do distanciamento oportunizado pela literatura. A realidade pode ser suavizada pela poética do texto. A arte de ler "abre caminho em direção à interioridade, aos territórios da afetividade, das emoções, da sensibilidade; a tristeza ou a dor podem ser dominadas. Os que abrem espaços de leitura abrem o espaço íntimo, subjetivo" (PETIT, 2009, p. 108).

\section{Considerações finais}

Os achados da investigação sobre livros, leituras e leitores na e para a EJA, no âmbito da política educativa recente, implantada como uma resposta ao problema da formação de leitores, se articulam com pressupostos teóricos da constituição de história de leitura e as questões socioculturais dos jovens em processo de escolarização. Concluise que os acervos de literatura para os estudantes da modalidade EJA do ensino fundamental e médio, servem de mote para pensar as articulações possíveis que se dão pela oferta de livros às escolas públicas do País e as ações desenvolvidas para oportunizar a experiência de leitura aos jovens enquanto uma questão sociocultural.

A qualificação de práticas de leitura e de escrita na Educação Básica se associam à formação de professores bibliotecários, ao incentivo para criação de espaços e tempos de leitura na escola em todas às áreas do conhecimento, à mediação oportunizada no âmbito das atividades educativas do cotidiano, às funções da biblioteca escolar para além das demandas do currículo, à experiência de ler como fonte de saber e de sabor. 
Os avanços em termos da política educativa de leitura não podem ser reduzidos à seleção, aquisição e distribuição de obras literárias de qualidade à biblioteca escolar. Torna-se evidente a necessidade de assumir na escola projetos com maior articulação nos processos de ensino e aprendizagem, pautados pela mediação e valorização da fabulação, enquanto direito humano fundamental.

A leitura, como prática social, coloca o leitor diante do desconhecido, provoca novas experiências simbólicas. É portadora de uma práxis sociocultural, entrelaçada com o domínio da fruição e do lazer, responde às exigências da obrigatoriedade escolar e do mundo do trabalho, abrange gênero, práticas profissionais. Assim, é vista como referência plural.

Conclui-se ainda que livros, leitura e leitores formam uma tríade para a biblioteca da escola colocar a literatura em ação, tendo como pressuposto a mediação de leitura e sua função de multiplicar, prolongar e preservar experiências literárias. A biblioteca escolar pode se constituir, de forma efetiva, numa resposta estratégica para o enfrentamento dos processos de exclusão e numa relação saudável entre os jovens, a leitura e os livros, particularmente para restituir a cota de humanidade que habita em cada ser humano.

\section{REFERÊNCIAS}

ARENDT, Hannah. A condição humana. Rio de Janeiro: Forense Universitária, 2005.

BALL, Stephen J . Sociologia das políticas educacionais e pesquisa crítico-social: uma revisão pessoal das políticas educacionais e da pesquisa em política educacional. In: Políticas educacionais: questões e dilemas. Stephen J. Ball, Jefferson Mainardes (Orgs.). São Paulo: Cortez, 2011.

. Novos Estados, nova governança e nova política educacional. In APPLE, Michael; BALL, Stephen J. e GANDIN, Luís A. Sociologia da Educação: análise internacional. Porto Alegre: Penso, 2013.

BRASIL. Base Nacional Comum Curricular. Brasília: MEC, 2017.

Diretrizes Curriculares Nacionais da Educação Básica. Brasília: MEC, 2010.

. Lei de Diretrizes e Bases da Educação. Brasília: Senado Federal, 1996.

Programa Nacional Biblioteca da Escola (PNBE). Brasília: Ministério da

Educação, Secretaria de Educação Básica, 2010. 
CAMPELLO, Bernardete et. al. Situação das bibliotecas escolares no Brasil: o que sabemos? Biblioteca Escolar em Revista, Ribeirão Preto, v. 1, n. 1, p. 1-29, 2012.

CANDIDO, Antônio. Vários escritos. São Paulo: Duas Cidades, 2004.

CASTRILlÓN, Silvia. O direitos de ler e de escrever. São Paulo: Pulo do Gato, 2011.

CERRILLO, Pedro et al. Libros, lectores y mediadores: la formación de los hábitos lectores como proceso de aprendizaje. Cuenca: Universidad de Castilla-La Mancha, 2002.

DAYRELL, Juarez. A escola como espaço sociocultural. In: DAYRELL, Juarez (Org.). Múltiplos olhares sobre a educação e cultura. Belo Horizonte: Ed. UFMG, 1999.

LAJOLO, Marisa. Do mundo da leitura para a leitura do mundo. São Paulo: Ática, 2000.

LAJOLO, Marisa. ZILBERMAN, Regina. A formação da leitura no Brasil. São Paulo: Ática, 1996.

LEWIS, Clive Staples. A experiência de ler. Porto: Porto Editora, 2003.

MANGUEL, Alberto. Uma história da leitura. São Paulo: Companhia das Letras, São Paulo: Companhia das Letras, 1997.

ORLANDI, Eni Pucineli. A história do sujeito-leitor: uma questão para a leitura. Discurso e leitura. Campinas: Pontes, 1988.

PENNAC, Daniel. Como um romance. Rio de Janeiro: Rocco, 1993.

PETIT, Michèle. A arte de ler ou como resistir à adversidade. São Paulo: Editora 34, 2009.

PETIT, Michèle. Leituras: do espaço íntimo ao espaço público. São Paulo: Editora 34, 2013.

Os jovens e a leitura: uma nova perspectiva. São Paulo: Editora 34, 2008.

QUEIRÓS, Bartolomeu Campos. O livro é passaporte, é bilhete de partida. In: A formação do leitor. Leia Brasil - Programa de Leitura da Petrobrás, 1999.

Organizadores: Jason Prado e Paulo Cóndini.

RANGANATHAN, S.R. As cinco leis da biblioteconomia. Brasília: Briquet de Lemos, 2009.

THIOLLENT, Michel. Metodologia da pesquisa-ação. São Paulo: Cortez, 2011.

TIEPOLO, Elisiani Vitória. Uma política de leitura para todos: leitores e neoleitores. In: MACHADO, Maria Margarida. Em Aberto, Brasília, v. 22, n. 82, p. 121-133, nov. 2009. 
ZILBERMAN, Regina. A leitura e o ensino da literatura. São Paulo: Contexto, 1988.

Recebido em: 01/06/2017

Aprovado em: 02/05/2018 